\title{
EFFECT OF DIFFERENT AIR FLOW RATES ON THE COLLECTION OF ATMOSPHERIC MOLD SPORES OF DIFFERENT SIZES BY A SLIT IMPACTOR
}

\author{
ATIN ADHIKARI, BUSHRA SHAH, TEDDYE GANDY, OREOLUWA ADEYINKA \& GALELA SHEBANI \\ Department of Epidemiology \& Environmental Health Sciences, Jiann-Ping Hsu College of Public Health, \\ Georgia Southern University, USA
}

\begin{abstract}
Exposure to mold spores are associated with allergic sensitization, which is a risk factor for atopic asthma in a community. Small aerodynamic sizes of spores $(<10 \mu \mathrm{m})$ allow them to penetrate in the lower airways and produce damaging byproducts including allergens and other immunomodulators. Usually mold spores in ambient atmosphere are collected by impactors in air monitoring stations, which are operated in a single standard air flow rate. However, sampling efficiency of an impactor can change in different air flow rates. Because spore aerodynamic sizes vary a lot and atmospheric temperature and humidity can influence aerodynamic properties of airborne mold spores, we hypothesize that mold data acquired based on a single air sampling flow rate - as currently being reported by most ambient air monitoring stations - could be incomplete. In this study, we have collected atmospheric mold spores simultaneously at three different air flow rates $(5 \mathrm{~L}, 10 \mathrm{~L}$, and $15 \mathrm{~L}$ per minute) and samples were collected from four rural ambient locations in different days. VersaTrap ${ }^{\circledR}$ spore trap cassettes were used for sampling, which provide the sampling versatility to capture mold spores of 1.5-3.9 $\mu \mathrm{m}$. As hypothesized, we found a substantial difference between total spore concentrations collected at different air flow rates: $1.306 \pm 960,1.709 \pm 1.430,1.081 \pm 923$ spores $/ \mathrm{m}^{3}$ at $5 \mathrm{~L}, 10 \mathrm{~L}$, and $15 \mathrm{~L}$ per minute, respectively. Mold spores of Aspergillus/Penicillium (typically $<3 \mu \mathrm{m}$ aerodynamic diameter) showed less variability compared to Ascopsores and Cladosporium.
\end{abstract}

Keywords: bioaerosol, molds, impactor, fungal spore, air sampling, aerobiology.

\section{INTRODUCTION}

Exposure to mold allergens including mold spores [1] and hyphal fragments [2] are associated with allergic sensitization, which is a risk factor for atopic asthma in a community. Several previous studies demonstrated significant associations between asthma hospital admissions and airborne concentration levels of mold spores in outdoor environments [3]-[7]. Therefore, accurate exposure assessment of mold spores in the ambient atmosphere is important. Exposure assessment of bioaerosols, including molds is challenging because several important tasks are involved. These tasks include verifying and quantifying the presence of molds, identifying mold genera and species accurately, monitoring the efficiency of sampling instrument, monitoring the effectiveness of exposure control measures, and finally assessing inhalable exposure levels to molds. While several principles are presently utilized for sampling of molds, impaction appears to be the one of the most commonly used methods for collecting airborne mold or fungal spores from outdoor air. Impaction stress may have some effect on the viability of molds but this is not so important for assessment of mold spores because total enumeration of molds (as both viable and non-viable spores carry allergens) is essential with respect to allergic potentials of molds. There are several impaction based mold sampling techniques available. For instance, airborne mold spores are often identified and counted by a high-resolution light microscope after collecting them on a slide of a single-stage impactor, such as the Burkard Personal Volumetric Air Sampler (Burkard Manufacturing Company Ltd, Hertfordshire, UK), VersaTrap spore trap cassette (SKC, Inc., Eighty Four, PA, USA), Air-O-Cell sampling cassette (Zefon Analytical Instruments, 
Inc., St. Petersburg, FL, USA), CyClex BioAerosol Impact Sampler, and Micro5 Microcell (Environmental Monitoring Systems, Inc., Charleston, SC, USA), to mention a few. All these impactors have either rectangular (slit) or circular inlets. Spores are captured through these inlets not only by impaction, but also by spore particle inertia. Spores of larger sizes and greater inertia are drawn into the device at a faster rate that allows the largest spores to enter and being captured on a reservoir (sticky substrate), while the smaller ones pass by with exit air flow or into the second chamber. Here, in the second chamber or cassette, the airflow is faster and the particles that bypass the reservoir are smaller, while the remaining larger particles are captured again in the substrate. In this way, the successive reservoirs or cassettes capture successively smaller particles. The principle of inertial impaction of spores by a VersaTrap single-stage spore trap cassette with a slit type inlet is presented below in Fig. 1.

Most of the impactors for sampling of total mold spores are single-stage collectors and they may differ from one another with respect to their ability to efficiently collect mold spores of specific sizes. This ability is characterized by the cut-off size, $d_{50}$, defined as the aerodynamic diameter of mold spores $\left(d_{a}\right)$ that are collected with $50 \%$ efficiency by the impactor. In addition, these impactors also differ with respect to the uniformity of the mold spore deposit on the collection substrate, which is important for appropriate microscopic enumeration [8], [9]. As stated above, the impactors differ with respect to $d_{50}$ and spore collection efficiency of the same impactor can change at different sampling air flow rates because $d_{50}$ is calculated using the following equation, eqn (1):

$$
d_{50}=\sqrt{9 \frac{S t k_{50 \eta} W}{p_{p} V C}}
$$

where, $S t k=$ Stokes' number, that describes the behavior of a spore suspended in a fluid flow; $W=$ width of spore; $\eta=$ air viscosity; $p_{p}=$ particle density; $V=$ average air velocity in the sampling inlet nozzle; and $C=$ Cunningham slip correction factor [10]. For instance, collection efficiency ( $d_{50}$ for spores of various sizes) of VersaTrap spore trap cassette at air flow rates of $30,25,20,15,10$, and $5 \mathrm{~L} / \mathrm{min}$ are $1.5,1.7,1.9,2.3,2.8$, and $3.9 \mu \mathrm{m}$, respectively (according to the manufacturer publication 1642; available in www.skcin.com). In addition, spore aerodynamic sizes and atmospheric release properties may vary in different temperature and relative humidity of ambient air, which can interfere with the sampling efficiency [11], [12].

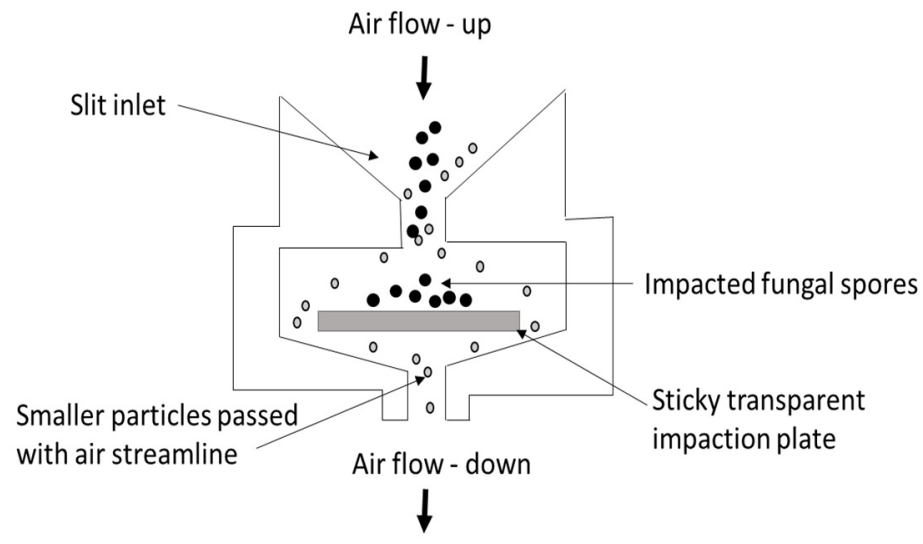

Figure 1: Principles of inertial impaction of fungal spores by VersaTrap spore trap. 
Despite these differences in spore collection efficiencies at different air flow rates by the same impactor, usually mold spores in ambient atmosphere are collected by impactors in a single standard air flow rate. Collection efficiency of impactors are mostly evaluated in the laboratory with generated bioaerosols or other kind of test particles, such as $\mathrm{NaCl}$ and PSL. Therefore, the degree of differences in collection efficiency for various airborne allergenic mold spores in ambient field environment by commonly used impactors are largely unknown.

In the present study, we hypothesize that mold data acquired based on a single air sampling flow rate - as currently being reported by most ambient air monitoring stations could be incomplete. To test this hypothesis in this study, we have collected atmospheric molds spores simultaneously at three different air flow rates by VersaTrap spore trap cassette and samples were collected from four rural ambient locations in USA. Concentration levels of total spores and some common allergenic spore types were determined when collected at three different air flow rates and compared.

\section{EXPERIMENTAL DESIGN AND METHOD}

\subsection{Sampling locations}

Four rural and semi-urban outdoor locations in Georgia, USA were selected for sampling of airborne mold spores. Due to a lot of cotton farming in close proximity and other agricultural operations we anticipated higher levels of mold spores in these locations. Selected locations were within 10-mile distances from each other. Three sites were selected in each location for simultaneous sampling of mold spores at three different air flow rates. These sites were 1.5 $\mathrm{m}$ apart from each other. All samples were collected at $1.5 \mathrm{~m}$ breathing height using three sampling tripods. In total 36 samples were collected from 12 sampling sites in four locations.

\subsection{Sampling instrument and microscopic analysis of mold spores}

Spores were collected by the VersaTrap ${ }^{\circledR}$ spore trap cassettes (SKC, Inc.), which provide the sampling versatility to capture mold spores of wide size range from 1.5 to $3.9 \mu \mathrm{m}$. This sampler was previously used in various field studies including assessment of mold spores after Hurricane Katrina in New Orleans, Louisiana [13]. We collected atmospheric molds spores simultaneously at three different air flow rates of 5 liters, 10 liters, and 15 liters per minute. As shown in the Fig. 1, the narrow-slit inlet of the VersaTrap ${ }^{\circledR}$ focuses ambient mold spores and other particles toward the clear glass slide coated with a sticky substrate. We collected air sample using three pumps (two models were utilized: AirchekXR 5000 and OMNI 400), which can continuously run quietly with air flow rates of up to 15 liters/minute. Three parallel samples were collected for one hour during each sampling campaign and altogether 12 campaigns were conducted in different days. All pumps were calibrated before sampling by using a DryCal defender calibrator (SKC, Inc.). Temperature and relative humidity were measured at the start of sampling and at the end of sampling each time of the day. All the VersaTrap ${ }^{\circledR}$ spore trap cassettes were opened and thin transparent sticky collection media of the samplers were placed on another glass slide. These collection media were then stained with lactophenol and cotton blue, covered with a $25 \times 25 \mathrm{~mm}$ cover glass, mounted with nail enamel, and examined under a high-resolution light microscope at $400 \times$ and $1000 \times$ magnifications. Spores were identified using identification manuals and reference slides. Raw spore counts were converted into airborne concentrations (spores per cubic meter of air or spores $/ \mathrm{m}^{3}$ ) based on air flow rate and the duration of sampling. Control field blank 
and media blank samples were collected alongside the sampling. Temperature and relative humidity $(\mathrm{RH})$ readings were taken using a thermohygrometer (Fisher Scientific, Hampton, NH, USA).

\section{RESULTS AND DISCUSSION}

Altogether 22 different mold spore types were identified in collected air samples and several types of unidentified spores were also observed. Total spore concentrations in four sampling locations ranged from 247 spores $/ \mathrm{m}^{3}$ to 3763 spores $/ \mathrm{m}^{3}$, which were recorded at $15 \mathrm{~L} / \mathrm{min}$ and $5 \mathrm{~L} / \mathrm{min}$, respectively. Mean total spores concentrations in three different air flow rates ranged from 1081 spores $/ \mathrm{m}^{3}$ to 1709 spores $/ \mathrm{m}^{3}$, which are close to previous data reported in other areas of the US, when impaction based rotorod sampling method was utilized [14]. The most prevalent airborne mold spores observed in four sampling locations were Aspergillus/Penicillium, Ascospores, Cladosporium, and Basidiospores. The common spores in the ascending order according to their aerodynamic sizes were: Aspergillus/Penicillum $<$ Ascospores $<$ Basidiospores $<$ Cladosporium $<$ Smut/Myxomycete spores $<$ Alternaria $<$ Epicoccum. Microscopic sizes of these spores were consistent to previous observations in other areas of USA [15]. Therefore, the expected aerodynamic sizes of these spores can range from 2.6-4.8 $\mu \mathrm{m}, 3.7-7.5 \mu \mathrm{m}, 5.2-8.3 \mu \mathrm{m}, 5.2-10.9 \mu \mathrm{m}, 8.3-11.0 \mu \mathrm{m}, 11.2-17.8 \mu \mathrm{m}$, and $15.7-22.0 \mu \mathrm{m}$ [15], respectively. Because of these wide variations in aerodynamic sizes the anticipated collection efficiency by VersaTrap at different sampling air flow rates was expected to differ a lot.

We have observed these variations indeed. Mean, median, standard deviation, and inter quartile range of the concentrations of common airborne mold spores are presented in Table 1. As shown in the Table $1,5 \mathrm{~L} / \mathrm{min}$ and $10 \mathrm{~L} / \mathrm{min}$ sampling flow rates were more effective for sampling of Aspergillus/Penicillium, Cladosporium, Periconia, and Torula spores whereas $15 \mathrm{~L} / \mathrm{min}$ air flow rate was more effective for Ascospores. Basidiospores were almost equally collected by all three sampling air flow rates. Fig. 2 shows the variations of total airborne spore concentrations in 12 sites when collected at three different air flow rates. In most cases $10 \mathrm{~L} / \mathrm{min}$ air flow rate showed higher concentrations compared to $5 \mathrm{~L} / \mathrm{min}$ and $15 \mathrm{~L} / \mathrm{min}$ flow rates. Fig. 3 shows overall concentrations of total airborne spores in all sites by box plots when air samples were collected at three air flow rates. The lower and upper boundaries of the box specify the 25th and 75 th percentiles, respectively. The line within the box indicates the median and the whiskers above and below the box indicate the 95 th and 5 th percentiles, respectively. Although Fig. 2 shows noticeable variations in total spore data between three different flow rates at 12 individual sites, we did not find statistically significant differences by one way ANOVA $(p=0.449$ when $\log$ transformed data were used), when all total spore data were compared between three air flow rates.

Similar to total spores, we have also compared site specific variations and overall variations of Aspergillus/Penicillium (Figs 4 and 5), Ascospores (Figs 6 and 7) and Cladosporium (Figs 8 and 9). In most cases $10 \mathrm{~L} / \mathrm{min}$ air flow rates were more effective than other two flow rates for collecting all these spore types.

Temperature and $\mathrm{RH}$ in all locations ranged from 15.9 to $25.9^{\circ} \mathrm{C}$ (mean $\pm \mathrm{SD}=20.4 \pm$ $5.3^{\circ} \mathrm{C}$ ) and 29.5 to $86.5 \%$ (mean $\pm \mathrm{SD}=52.8 \pm 18.4 \%$ ), respectively. We categorized all data into three groups based on variations in temperature, relative humidity, and sampling time, and compared by ANOVA. No significant differences were observed (data not shown).

We have also conducted multiple linear regression analysis using PROC GLM (Generalized Linear Model; SAS 9.4 version) to understand the relationship between air flow rates and concentrations of total spores, Aspergillus/Penicillium, Ascospores, and 


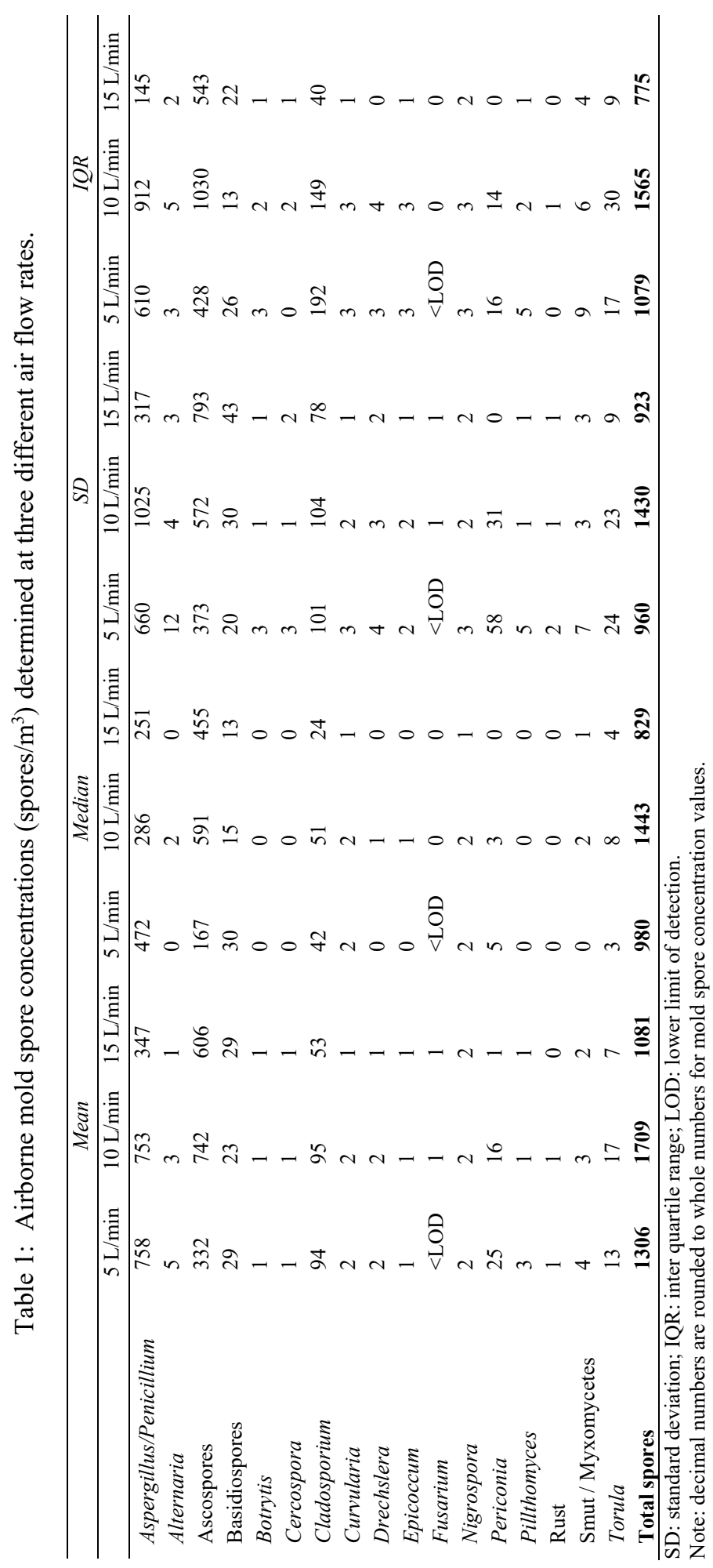




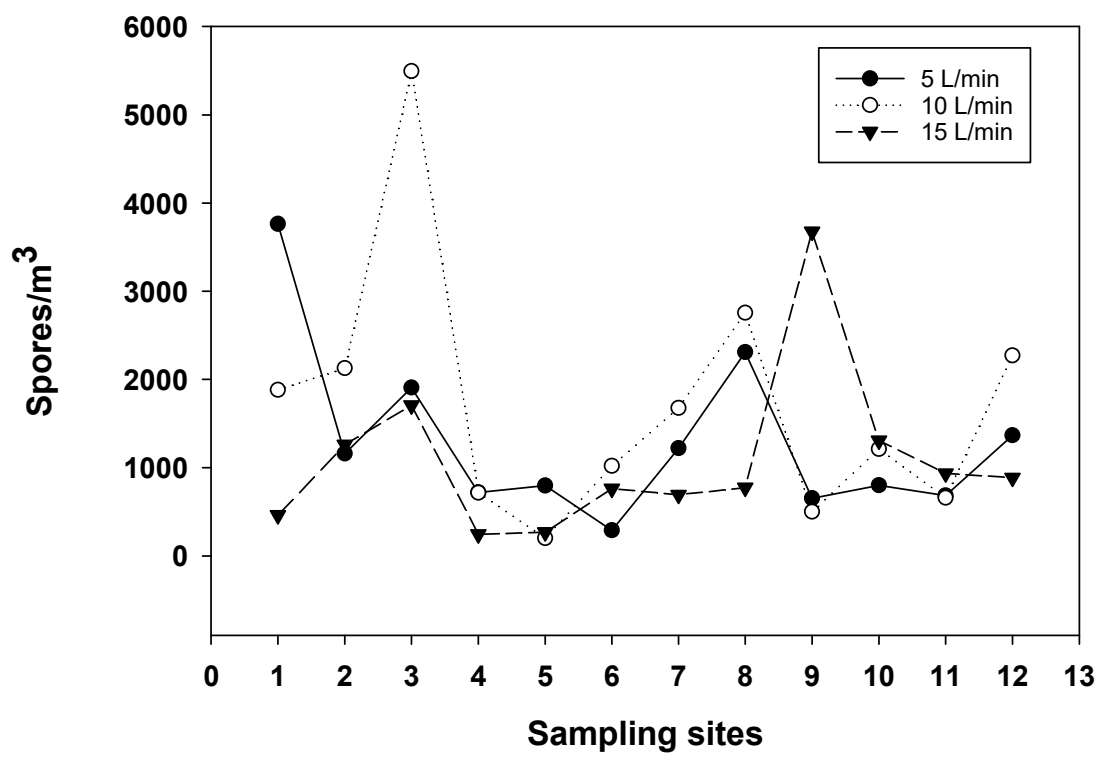

Figure 2: Variations of total airborne mold spore concentrations at 12 sites when air samples were collected at three different sampling air flow rates.

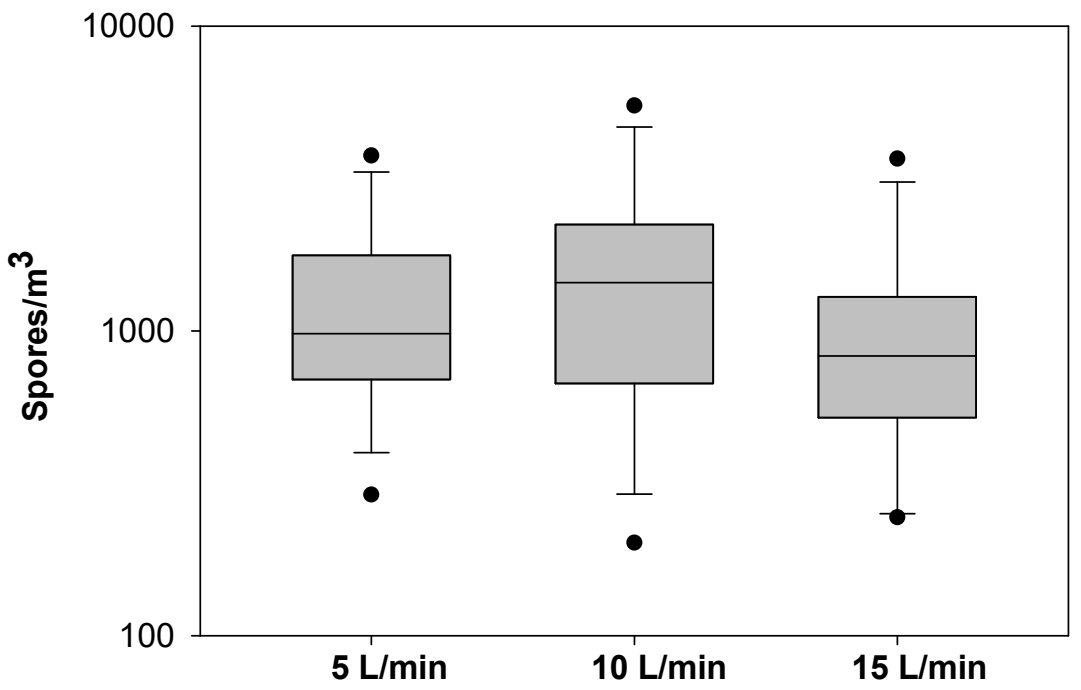

Figure 3: Overall total spore concentrations in all sampling sites when air samples were collected at three different sampling air flow rates. 


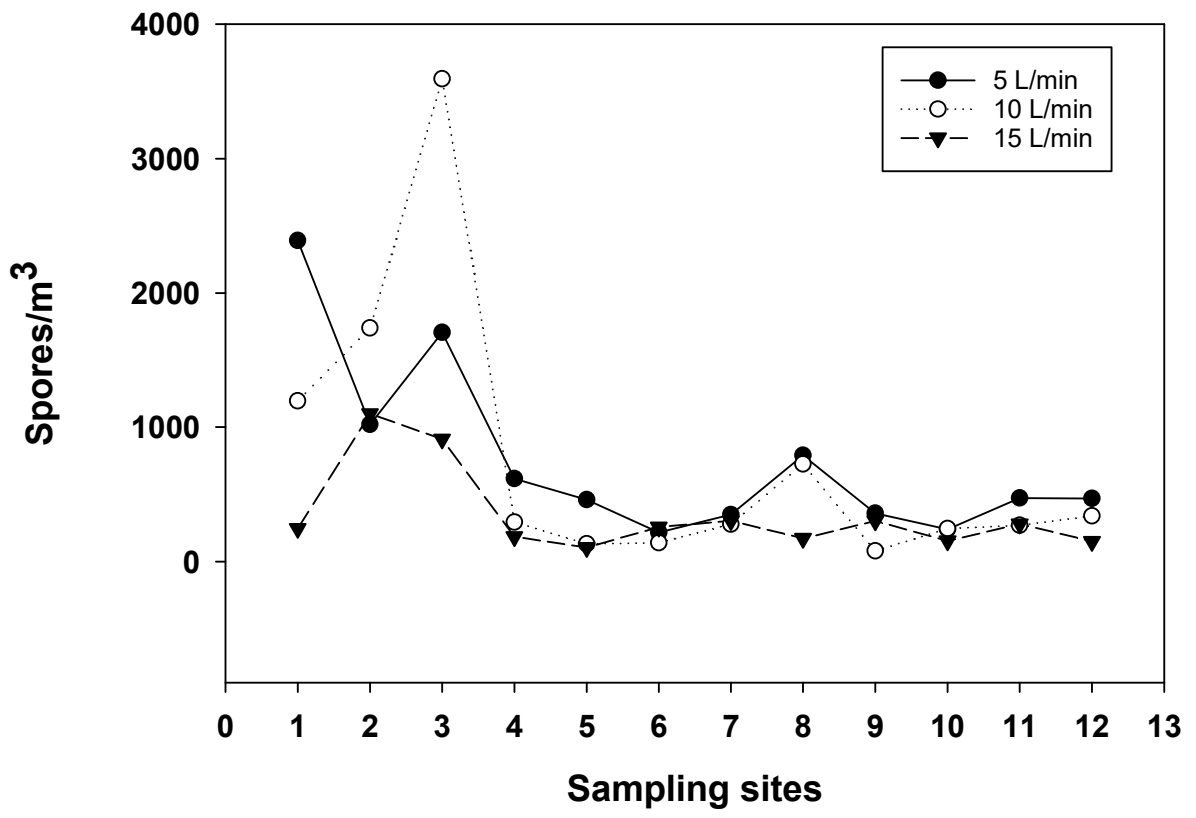

Figure 4: Variations of Aspergillus/Penicillium spore concentrations at 12 sites when air samples were collected at three different sampling air flow rates.

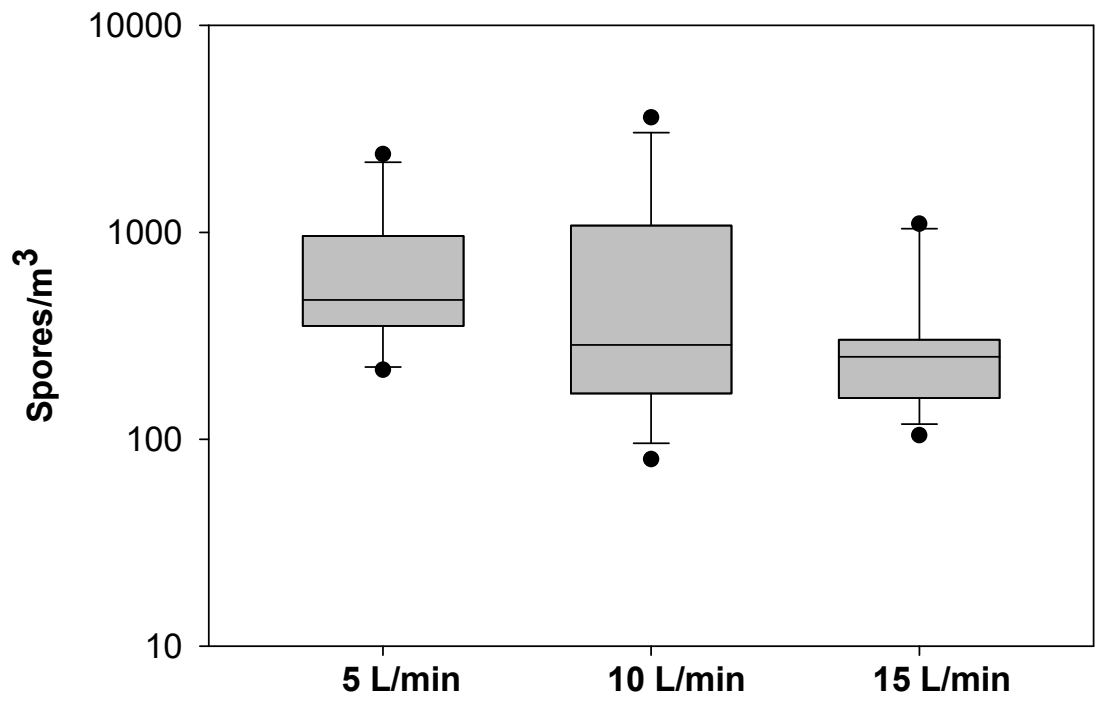

Figure 5: Overall concentrations of Aspergillus/Penicillium spores in all sampling sites when air samples were collected at three different sampling air flow rates. 


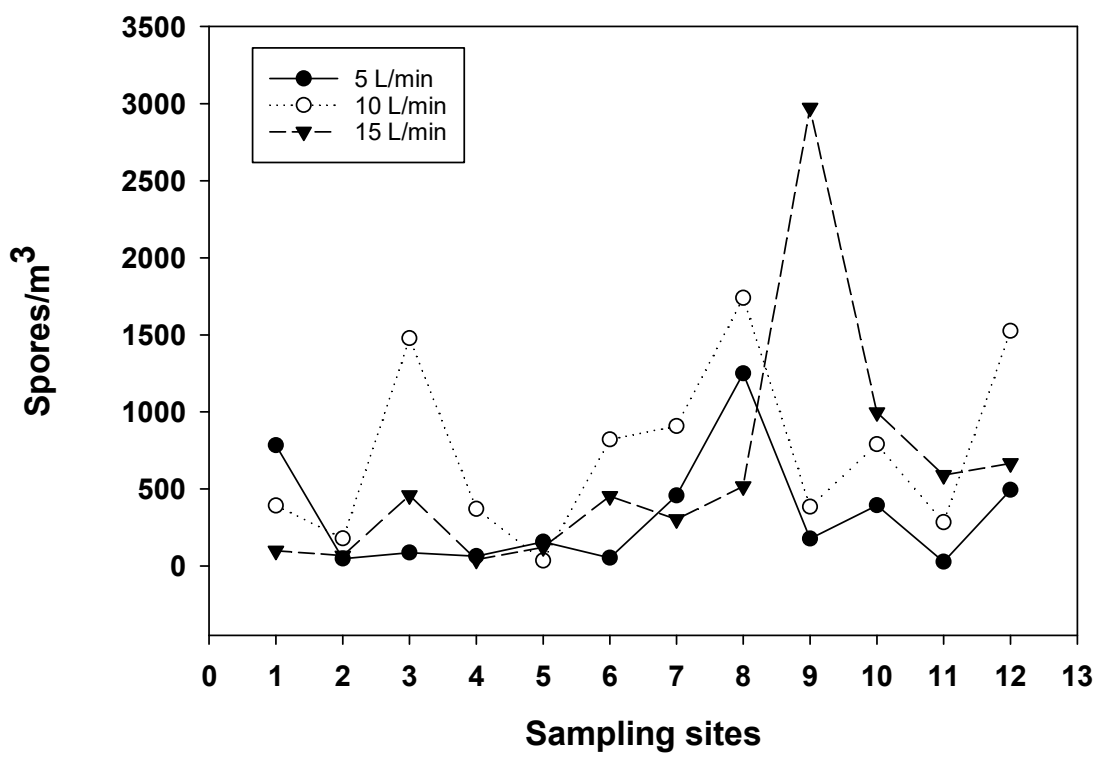

Figure 6: Variations of Ascospore concentrations at 12 sites when air samples were collected at three different sampling air flow rates.

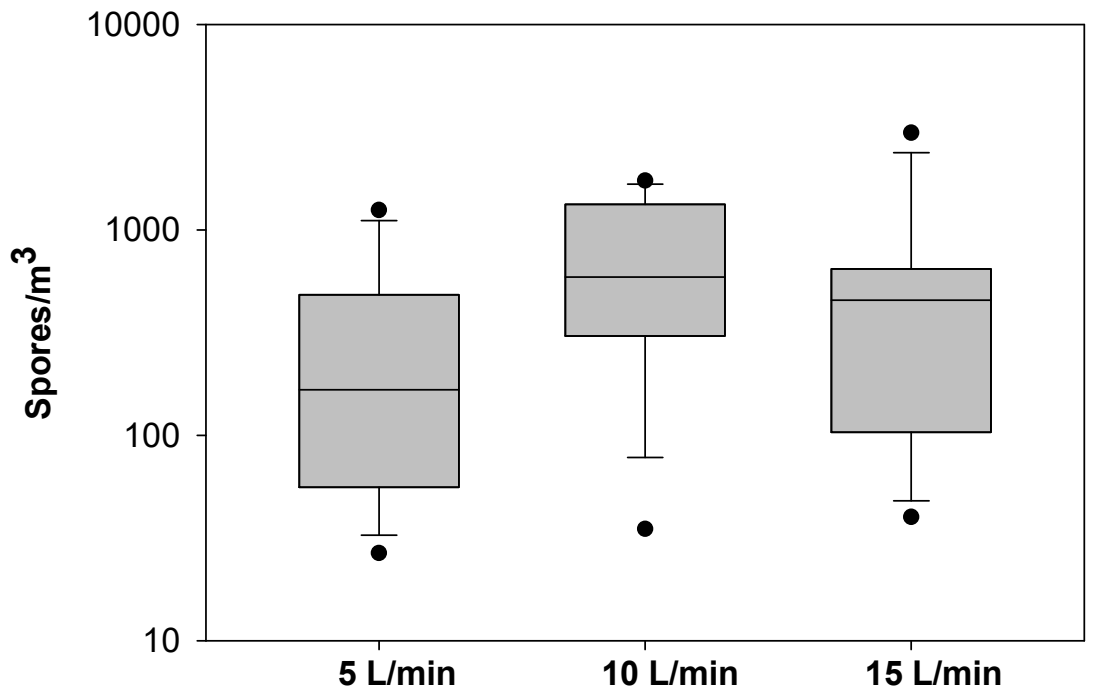

Figure 7: Overall concentrations of Ascospores in all sampling sites when air samples were collected at three different sampling air flow rates. 


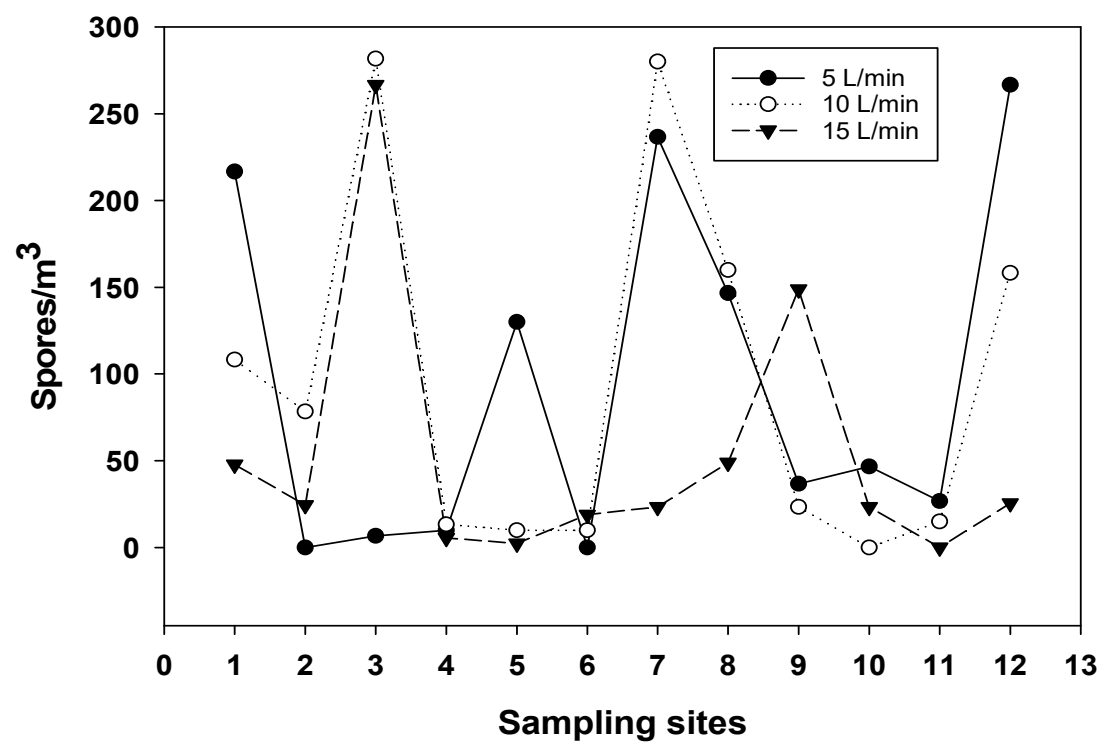

Figure 8: Variations of Cladosporium spore concentrations at 12 sites when air samples were collected at three different sampling air flow rates.

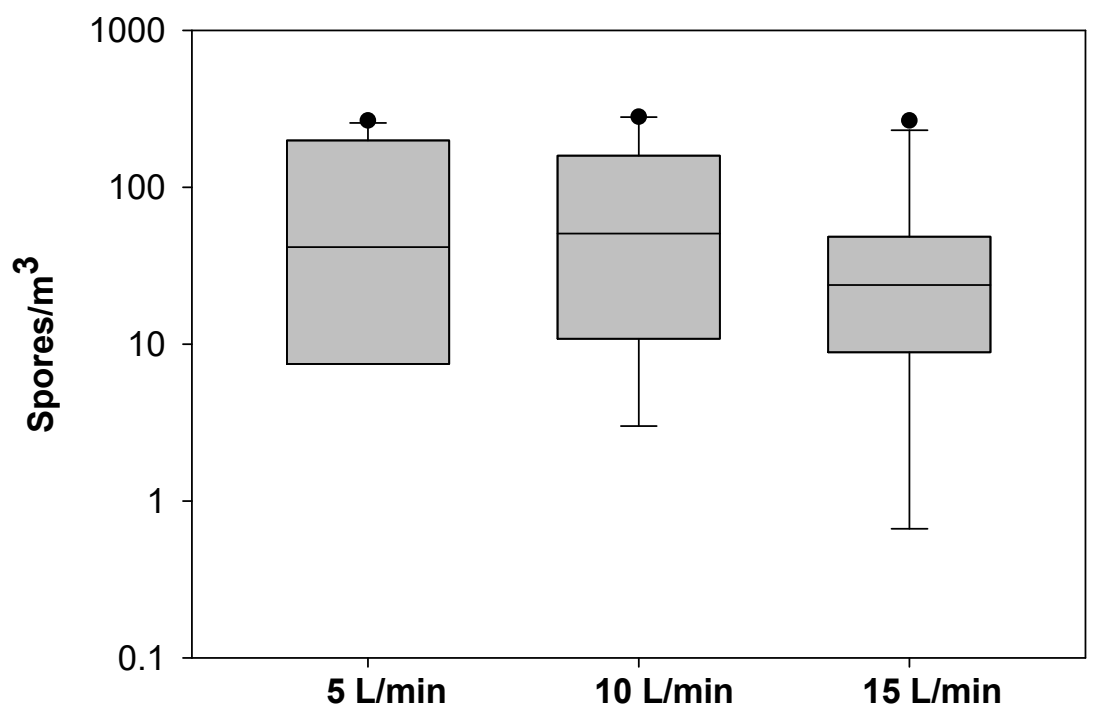

Figure 9: Overall concentrations of Cladosporium spores in all sampling sites when air samples were collected at three different sampling air flow rates. 
Cladosporium when adjusting for temperature and RH. No significant relationships $(p>0.05)$ were observed. Probably limited amount of data is the reason behind these observations.

Our results underscore the importance of sampling air flow rate for mold exposure assessment and consequently in investigations and reporting for mold-related atopic asthma.

To conclude, our preliminary data showed that $10 \mathrm{~L} / \mathrm{min}$ air flow rate is more effective for collecting most airborne mold spores, although $15 \mathrm{~L} / \mathrm{min}$ air flow rate is recommended for VersaTrap spore trap as the optimal flow rate. This finding, however, should be verified in large-scale studies.

\section{DISCLAIMER}

Reference to any company or specific commercial product does not necessarily constitute or imply their endorsement, recommendation, or favoring by the group of authors or by Georgia Southern University.

\section{ACKNOWLEDGEMENT}

This study was supported by a grant from the Faculty Development Committee, Georgia Southern University. All authors are grateful for this financial support. Technical assistance of Mrs. Jacquelyn Lewis is highly appreciated by the authors.

\section{REFERENCES}

[1] Horner, W.E., Helbling, A., Salvaggio, J.E. \& Lehrer, S.B., Fungal allergens. Clinical Microbiology Reviews, 8(2), pp. 161-179, 1995.

[2] Green, B.J., Tovey, E.R., Sercombe, J.K., Blachere, F.M., Beezhold, D.H. \& Schmechel, D., Airborne fungal fragments and allergenicity. Medical Mycology, 44(sup1), pp. 245-255, 2006.

[3] Delfino, R.J., et al., The effect of outdoor fungal spore concentrations on daily asthma severity. Environmental Health Perspectives, 105(6), p. 622, 1997.

[4] Denning, D.W., O'driscoll, B.R., Hogaboam, C.M., Bowyer, P. \& Niven, R.M., The link between fungi and severe asthma: a summary of the evidence. European Respiratory Journal, 27(3), pp. 615-626, 2006.

[5] Osborne, M., et al., Specific fungal exposures, allergic sensitization, and rhinitis in infants. Pediatric Allergy and Immunology, 17(6), pp. 450-457, 2006.

[6] Pongracic, J.A., et al., Differential effects of outdoor versus indoor fungal spores on asthma morbidity in inner-city children. Journal of Allergy and Clinical Immunology, 125(3), pp. 593-599, 2010.

[7] Tham, R., et al., Outdoor fungi and child asthma health service attendances. Pediatric Allergy and Immunology, 25(5), pp. 439-449, 2014.

[8] Grinshpun, S.A., et al., Collection of airborne spores by circular single-stage impactors with small jet-to-plate distance. Journal of Aerosol Science, 36(5), pp. 575-591, 2005.

[9] Grinshpun, S.A., Adhikari, A., Cho, S.H., Kim, K.Y., Lee, T. \& Reponen, T., A small change in the design of a slit bioaerosol impactor significantly improves its collection characteristics. Journal of Environmental Monitoring, 9(8), pp. 855-861, 2007.

[10] Trunov, M., Trakumas, S., Willeke, K., Grinshpun, S.A. \& Reponen, T., Collection of bioaerosol particles by impaction: effect of fungal spore agglomeration and bounce. Aerosol Science \& Technology, 35(1), pp. 617-624, 2001.

[11] Pasanen, A.L., Pasanen, P., Jantunen, M.J. \& Kalliokoski, P., Significance of air humidity and air velocity for fungal spore release into the air. Atmospheric Environment. Part A. General Topics, 25(2), pp. 459-462, 1991. 
[12] Reponen, T., Grinshpun, S.A., Conwell, K.L., Wiest, J. \& Anderson, M., Aerodynamic versus physical size of spores: measurement and implication for respiratory deposition. Grana, 40(3), pp. 119-125, 2001.

[13] Schwab, K.J., et al., Microbial and chemical assessment of regions within New Orleans, LA impacted by Hurricane Katrina. Environmental Science \& Technology, 41(7), pp. 2401-2406, 2007.

[14] Adhikari, A., et al., Performance of the Button Personal Inhalable Sampler for the measurement of outdoor aeroallergens. Atmospheric Environment, 37(34), pp. 4723-4733, 2003.

[15] Lee, S.A., Adhikari, A., Grinshpun, S.A., McKay, R., Shukla, R. \& Reponen, T., Personal exposure to airborne dust and microorganisms in agricultural environments. Journal of Occupational and Environmental Hygiene, 3(3), pp. 118-130, 2006. 